\title{
Industrial High Pressure Processing of Foods: Review of Evolution and Emerging Trends
}

\author{
Francisco Purroy Balda, Beatriz Val Aparicio and Carole Tonello Samson \\ Hiperbaric, S.A. Condado de Treviño, Burgos 609001, Spain
}

Received: July 6, 2012 / Published: October 20, 2012.

\begin{abstract}
High Pressure Processing (HPP), in the range of $200 \mathrm{MPa}$ to $600 \mathrm{MPa} / 29,000$ psi to 87,000 psi, is the most advanced emerging non-thermal processing technology for food. The constant improvements of high pressure equipment concerning productivity and production costs have facilitated the increase of industrial uses of the technology. This paper reviews some of these advances in high pressure food processing including development of new functional beverages the new value proposals being offered by copackers substitution of traditional thermal techniques for novel product manufacturing and refrigerated services suppliers. Substitution of thermal treatments for meat processing and tenderisation of low value meat cuts.
\end{abstract}

Key words: Industrial HPP equipment, functional products, toll processing, meat tenderization, HPP.

\section{Introduction}

High pressure processing is a non-thermal food preservation process. This technology focuses on avoiding spoilage of products while preserving its quality attributes. Food spoilage has several grades and may be caused by a wide range of factors: from enzymatic spoilage for example polyphenol oxidase (PPO) on fruits or proliferation of spoiling microorganisms which activity results in changes in color, or texture, to the survival or growth of some pathogenic microorganisms causing infections or intoxications.

In the past years a change in consumer's trends took place. At the end of the last century, consumers focused their demands in safety and price of the products, so food industry was prone to over process its products, loosing quality attributes. Nowadays, consumers ask for natural, free additives, and fresh products [1-4]. Following these current trends, new products that are labeled as "natural”, "minimally

Corresponding author: Francisco Purroy, technical sales manager, research field: HPP applications for Hiperbaric. E-mail: f.purroy@hiperbaric.com. processed”, with no artificial ingredients and a clean label have pushed the level of implementation of emerging processing techniques.

The effect of HPP is almost instantaneous (sound velocity) and uniform (Pascal principle), as pressure transmission is not mass time dependent [5]. This fact results in a shorter process time if compared with thermal treatments. Shortened process time is a characteristic of novel non thermal technologies, also the key to improve productivity and thus, spread the technology around the world. The uniformity and instantaneity of the process makes it easier pass from a laboratory to industrial scale, due to the efficiency is independent on the products size and volume [1].

Technically speaking, HPP technology is based on Le Chatelier principle. It means that pressure favors all the reactions with a drop of volume. On the contrary, reactions accompanied by an increase of volume are slowed down.

The study of the effects of high hydrostatic pressure on the molecules integrating food products has strongly increased in recent years [6]. These researches are targeted to understand the effects of 
HPP on the whole food matrix. One of the main characteristics of high hydrostatic pressure technology is the maintenance of covalent bonds that constitute food biomolecules. High pressure only affects weak bonds such as Van der Waals forces, hydrogen or hydrophobic bridges, changing the tridimensional structure of molecules without breaking or dividing them, so nutritional composition is not affected by HPP treatment. The effect of high hydrostatic pressure on biocompounds is not only the cause sensory changes in the product but also vegetative microorganism destruction which increases shelf life and food safety. HPP causes several damages in cell membranes, in some enzymes implicated in cell replication by denaturalization and losing their native conformation and cell homeostasis, among other molecules and processes. Vegetative microorganism inactivation is closely related to microorganism species and strain and to pressure. The higher pressure and the longer holding time, the more microbial inactivation [7].

HPP is proved to be effective and economically feasible, showing now consistent double-digit growths. Being increasingly implemented in the last decade, solutions like HPP are opening other options to the food industry worldwide: developments in the last 24 months include both application or product innovations, and new value-added industrial processing scenarios for the food sector.

HPP technology emerged as a post-harvest, post packaging technique for high value food products in the late 90's. The first commercial application of HPP took place in Japan, used in the jam and fruit puree industry (1990). It was very early for HPP technology, machines were nearly prototypes, and often did not fit food industry requirements, such as productivity or traceability. Despite these inconveniences at the beginning, HPP technology was accepted by consumers and industry as a useful technique for several aspects in food industry, such as shelf life improvement, hygienization and pathogen destruction, custacean meat extraction, development of new functional products or value adding refrigerated services.

\section{HPP Industrial Equipment}

The key parameters for the success of high pressure technology are safety, reliability and productivity, ease of installation, operation, servicing and ease of cleaning [8]. This basis has been taking into account when designing industrial HPP equipment. Machines installed in food industry have to be compact, and their design must also consider the fact that these machines will perform many cycles per hour at pressures up to $600 \mathrm{MPa}(87,000 \mathrm{psi})$. This means subjecting the equipment to high mechanical stresses, so materials are a very important factor implied in the design, too.

The design of the first HPP equipment for food industry was based on the same parameters that the ones used in other industries such as chemical, ceramics or metallurgical. It was not considered that in food industry process cycles would be shorter. Equipment was designed with a vertical vessel with one plug only so the load/unload of the product was really slow. Placing the vessel in horizontal position changed the scenario of HPP in the food industry. The first horizontal machine was made by GEC ALSTOM ACB for the Spanish meat company Espuña [8] in 1998. Now, $97.5 \%$ of the machines installed in the last 24 months were horizontal.

High pressure process in horizontal equipment has several advantages compared to vertical designed equipment. Product is loaded in plastic conveyors and then pushed inside the vessel. Afterwards, the vessel moves inside the yoke. The yoke is the metallic part of the machine which avoids opening the plugs and therefore, maintains pressure inside the vessel. First the vessel is filled with low pressure water with the plugs closed. When it is completely full, the intensifiers start to pump high pressure water up to the desired pressure. When holding time is over, water is 
discharged in a few seconds by opening the releasevalves, and finally the vessel returns to the first step and can be loaded with product again. The new product in the conveyors will push processed product and a new cycle can get started.

There are the advantages of the horizontal design for the food industry [8].

Loading/unloading process is easier than in other designs. With a horizontal machine cranes are not necessary, so time, energy and money are saved.

The installation of the equipment is easier due to the size (small height compared with vertical machines). This design avoids the requirement of many levels in the construction of the industry.

Traceability is better, an essential factor in food industry, by reducing the risk of confusing processed and unprocessed product [5]. The loading process takes place in one of the ends while the other part of the equipment is prepared to the reception of the processed product.

Although horizontal designs solved many of the challenges for HPP in food industry, new ones have appeared along this last years. One of the new trends in HPP machines design is the addition of intensifiers in order to reduce the coming up time (time taken to reach the desired pressure), resulting in shorter cycles and therefore more productivity (coming up time overage in 2000 up to $600 \mathrm{MPa} / 87,000$ psi was $5 \mathrm{~min}$; in 2010 it decreased up to $2.5 \mathrm{~min}$ )

Other main parameter for the implementation of high pressure processes in food industry is the increase in vessel size. The largest vessel in late 90's had a volume of $215 \mathrm{~L}$ and it has been improved to $420 \mathrm{~L}$ in 2011. In line with this trend, the average industrial vessel volume in production has doubled in the last decade [8] and the number of cycles per hour has also increased by reducing time of low pressure operations (machine movements and low pressure operations).

Investment and processing costs is also a factor of vital importance for the spread of high pressure technology. They have been reduced up to three fold in the last decade thanks to the technical improvements that lead in shorter process time and higher productivity. Nowadays the investment for a HPP machine is placed in a range of 500,000€-2,000,000€ (US\$750,000-3,000,000) depending on the volume of the vessel. With these prices, the amortization, energy cost and maintenance cost we could estimate the processing cost per kilo (Table 1) in a 3 min holding time at $600 \mathrm{MPa}$ with a volumetric efficiency of $60 \%$.

As in January 2012, there were around 160 high pressure equipment installed in food industries all over the world; the main markets are North America, the European Union, Japan, Korea, Australia and New Zealand. HPP equipment may be also found in Peru, Chile and China. The companies that have decided to implement HPP are very different among them, from small companies with niche markets to large industrial groups [8]. Sometimes HPP equipment is shared by companies, so usually the number of companies commercializing HPP products is higher than the number of equipment installed.

Fifty five percent of the HPP equipment installed around the world is located in North America (USA, Canada, and Mexico). Since the United States Department of Agriculture recommended HPP as a suitable method for controlling Listeria monocytogenes in ready to eat meat and poultry products, this technology has gained acceptance from consumers and companies. Canada and Mexico use HPP in order to control pathogens in products destined to export to USA, their main foreign market. Mexico has become the world leader in HPP avocado and guacamole. Both are some of the most successful examples of products treated by high pressure.

Nowadays, most of the equipment installed around the world, $44 \%$ is dedicated to process fruit\&vegetable based products [8]. This high percentage is due to the fact that avocado industry has been one of the main drives for this innovative technology. 
Table 1 Outputs and processing cost of hiperbaric machine.

\begin{tabular}{|c|c|c|c|c|}
\hline \multicolumn{5}{|c|}{ Maximum pressure (bar)/vessel volume (L) } \\
\hline & $6000 / 55$ & $6000 / 135$ & $6000 / 300$ & $6000 / 420$ \\
\hline Output $^{\mathrm{a}}\left(\mathrm{kg} \mathrm{h}^{-1}\right)\left(\mathrm{lbs} \mathrm{h}^{-1}\right)$ & $283(624)$ & $630(1478)$ & 1565 (3451) & $2043(4505)$ \\
\hline Processing cost ${ }^{\mathrm{b}}\left(€ \mathrm{~kg}^{-1}\right)\left(\$ \mathrm{lb} \mathrm{s}^{-1}\right)$ & $0.127(0.087)$ & $0.107(0.072)$ & $0.070(0.047)$ & $0.066(0.045)$ \\
\hline
\end{tabular}

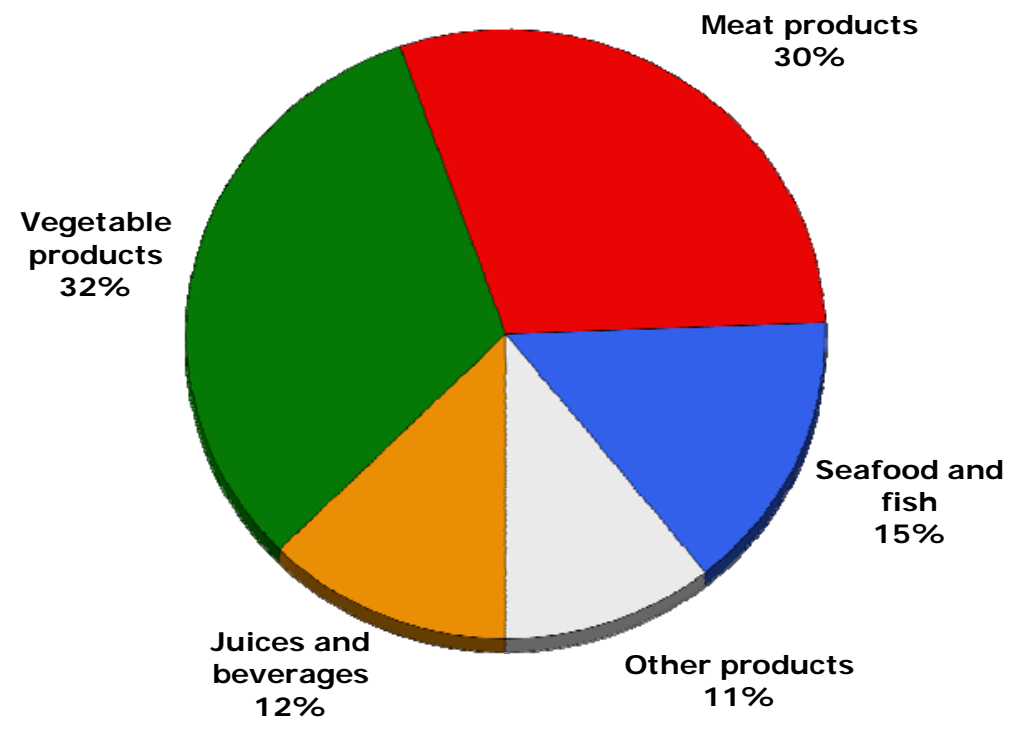

Fig. 1 Distribution of HPP equipment in food industry (Hiperbaric S.A. 2012).

Following fruit and vegetable products industry, meat industry owns $30 \%$ (Fig. 1) of the machines installed in the world by 2012. In the last years meat industry has been the sector with the fastest rising rate in food industry. This increase is due to the risk of contamination with Listeria monocytogenes in most of the products. Nowadays the largest meat producer using HPP is Hormel Foods in USA.

Shucking meat from crustaceans and opening bivalves is another application of high pressure technology in food industry. Seafood products industry takes up the third place with $15 \%$ of the machines installed around the world. Shucking meat from mollusk or crustaceans is not the only application for seafood products, ready to eat products is another main application for HPP in this sector.

\section{Commercial Trends}

Although increasing shelf life in food products may be considered as the main application of high pressure technology we can find some companies using HPP in a different way. Development of new products and toll processing are the most common.

\subsection{Development of New Functional Products}

Recent researches focus on antimutagenic \& antioxidant compounds. New functional products have been developed in the last decade, and HPP has played a vital role. The majority of the functional compounds are sensible to thermal treatments, but they resist high pressure treatment. One example of these new trends in food industry is pomegranate juice. According to Ferrari et al. [9], high pressure preserves color and bioactive compounds in pomegranate juice, improving its quality compared to thermal treatment. Not only pomegranate but also broccoli, quite common in some countries such as Czech Republic, has been researched in order to develop and commercialize new products 
$[10,11]$

Besides juice industry, dairy products are another promising field to implementation of HPP equipment for preserving functional compounds.

Fonterra (http://www.fonterra.com), a cooperative group from New Zealand aimed on dairy products, made research and created a market space for probiotic, functional juices in which no culture management was necessary and an extended shelf-life was achieved. HPP seems to offer a solution in probiotic propositions, in which a thermal pasteurization is not an option as heat inactivates the probiotic strains. Fonterra's research in dairy products, such as milk, different milk fractions or yogurt, has been issue of several patents. By optimizing pressure/time conditions they preserve probiotic strains of lactic acid bacteria or avoid products spoilage by molds or yeasts [12-14]. One of Fonterra's high pressure processing patent is the basis of a commercial beverage using colostrum [15]. Fonterra signed its first license in 2008 for the industrial production to new image, a manufacturer from New Zealand that commercializes colostrum drink in the Asian market under the brand: $\mathrm{Col}+$ (http://www.colplus.com). A High pressure treatment of $600 \mathrm{MPa}(87,000 \mathrm{psi})$ results in a shelf stable product up to six months at room temperature [16].

\subsection{Value Adding Refrigerated Services and Co-packing}

Toll processing of innovative technologies is a scheme that has been increasingly utilized in the food industry over the last five years. American Pasteurization Company was the first company that implemented HPP for toll processing. Afterwards AmeriQual (www.ameriqual.com), another American company installed a Hiperbaric 300 L unit (79 US gal)-600 MPa (87,000 psi) machine at their facilities in Evansville. In 2007, this company decided to install another $300 \mathrm{~L}$ machine, formerly used by Tyson to pasteurize oven roasted chicken products [16].

At the turn of the decade, innovative value services appear, now not only offered by co-packers but also by companies dedicated to serve food industries as logistic platform and integral refrigerated services solution. Such companies are strategically moving towards adding more value to their customers: now they target not only stock management, chilled supply chain or JIT deliveries. In a new business case, organizations offering refrigerated services are currently adding more value to their service, by offering new technological capabilities and granting customers the access to post-packaging techniques for shelf life extension or pathogen destruction. Thus food\&beverage industries which are shipping their products to these cold storage facilities can also benefit from other innovative processing solutions they do not have in their own facilities [17]. Millard refrigerated services (http://www.millardref.com) is an example of this new trend, they provide refrigeration and distribution services to major retail, food service and food distribution companies. Millard refrigerated services had added high pressure processing technology as a new value adding service for their customers with 3 machines, currently Hiperbaric 420 L.

\section{Emerging Trends}

In the next decade some HPP applications proved in laboratory will be scaled to industrial applications. The substitution of thermal treatments and meat tenderization are likely to become commercial applications in a few years.

\subsection{Substitution of Thermal Treatments for Meat Processing}

Extensive research carried out in Germany, New Zealand and the US over the last years led to the creation of new opportunities that are being adopted by food industries, including: a) substitution of traditional thermal treatments in the manufacturing of spreadable sausages, liver sausages and cooked-cured loin products. High pressure processing techniques developed in Germany are allowing manufacturers to 
eliminate heat steps in their process flow, in order to improve textures or achieve protein gelification and firmness. The high isostatic pressure step also offers dietary and sensory advantages, as it retains valuable micro-molecules such as aroma components and vitamins, whose bonds can not be modified by HPP process; b) Creation of new opportunities in the functional products space [18].

\subsection{Tenderization of Red Meats}

Although Bouton et al. made some investigations about meat tenderization [19], it seems now to be an important research field and also has strong commercial perspectives. The process has been developed by Australian and North American scientists. Tenderization can be obtained by subjecting meat cuts to a minimal high pressure process (2000 bars, a few minutes) a few hours after slaughter as once the meat has reached post rigor conditions. High pressure process results in an increase of meat hardness. Texture changes are caused by the effects of high pressure processes in some enzymes related to the development of meat tenderness, such as cahtepsins and calpains. This may be one of the reasons why high pressure must be applied a few hours after slaughter, in pre-rigor conditions in order to reach an increase in tenderness. If treatment is carried out in post-rigor state, hardness may be increased [20].

High pressure treatment of meat in pre-rigor conditions has multiple effects, not only tenderization. Results, after a treatment of 2,000 bars for a few minutes, have shown higher water binding in meat proteins, decrease collagen taste and better overall results. This is giving very interesting possibilities to industries willing to add value to low value beef and lamb cuts. Meat and livestock Australia (MLA) is aiming to take the project into industrial phase [20].

Hormel foods (www.hormelfoods.com) contemporaneously to the abovementioned research, has obtained in 2010 a patent for inhibitions of postmortem glycolysis by the use of high pressure processing. Processing meat cuts of pork, turkey, beef or chicken under pressures of a minimum $175 \mathrm{MPa}$ and maximum $320 \mathrm{MPa}$ for a few seconds or minutes in a right after slaughtering invention, inhibition of rigor mortis is achieved in the muscles, rendering improved juiciness, texture and palatability [21].

\section{Conclusions}

The major barriers to the implementation of HPP technology, mainly being: i) HPP is a batch technique which, in the recent past, gave low throughputs, and ii) requirements of high capital investment, are continuously being lowered thanks to advances in design and materials, making the economic scenarios and business cases for the implementation of such non thermal intervention easier for food industries in different sectors around the world. HPP tends to be more widely spread and accepted in a diverse spectrum of food sectors which pursue innovative value propositions and improved quality assurance, stock management and food safety.

\section{References}

[1] L.T. Nguyen, V.M. Balasubramaniam, Fundamentals of food processing using high pressure, Nonthermal Processing Technologies for Food 1 (2011) 3-19.

[2] D. Sorenson, M. Henchion, Understanding consumers' cognitive structures with regard to high pressureprocessing: A means-end chain application to the chilled ready meals category, Food Quality and Preference, 2010.

[3] H.B. Nielsen, Consumer perception of the use of high pressure and pulsed electric field technlogies in food production, Appetite 52 (2009) 115-126.

[4] M. Hugas, M. Garriga, J.M. Montfort, New mild technologies in meat processing: High pressure as a model technology, Meatscience 62 (2002) 359-371.

[5] H. Mújica-Paz, A. Valdez-Fragoso, C.T. Samson, J. Welti-Chanes, J.A. Torres, High pressure processing technologies for the pasteurization and sterilization of foods, Food Bioprocess Technol. 4 (2011) 969-985.

[6] K. Heremans, The effects of high pressure on biomaterials, Ultra High Pressure Treatments of Foods 2 (2002) 23-51. 
[7] E.P. Black, C.M. Stewart, D.G. Hoover, Microbiological aspects of high pressure food processing, Nonthermal Processing Technologies for Food 5 (2011) 51-71.

[8] C. Jung, C. Tonello, M. Lamballerie, High hydrostatic pressure food processing, Alternatives to Conventional Food Processing 6 (2011) 254-306.

[9] G. Ferrari, P. Maresca, R. Ciccarone, The application of high hydrostatic pressure for the stabilization of functional foods: Pomegranate juice, Journal of Food Engineering 100 (2010) 245-253.

[10] M. Houska, A. Landfeld, J. Strohalm, Comparison of heat and high pressure pasteurization of apple broccoli juice, New Food Digital.

[11] L. Mandelova, J. Totusek, Broccoli juice treated by high pressure: Chemoprotective effects of sulforaphane and indole-3-carbinol, High Pressure Research 27 (2007) 151-156.

[12] T. Carrol, P. Chen, M. Harnett, J. Harnett, Pressure treating food to reduce spoilage, Fonterra International Patent, 2004, WO2004032655.

[13] T. Carrol, H. Patel, K. Palmano, M. González Martín, J. Dekker, M. Collett, et al., High pressure processing of bioactive compositions, Fonterra International Patent,
2006, WO2006096074.

[14] K. Palmano, H. Patel, T. Carroll, D. Elgar, M. González Martín, High pressure processing of metal ions lactoferrin, Fonterra International Patent, 2006, WO2006096073.

[15] O. Hembry, Fonterra health drink thrives under pressure [Online], 2008, www.NZHerald.co.nz.

[16] C. Tonello, Case studies on high pressure processing of foods, Nonthermal Processing Technologies for Food 4 (2011) 36-50.

[17] Meat \& poultry staff, Millard launches high pressure processing, Meat\&Poultry, May 13, 2011.

[18] F. Purroy, Value adding refrigerated services through nonthermal processing techniques, International Meat Tech Sessions, Chicago, USA. Apr. 13-16, 2011.

[19] J.C Cheftel, J. Culioli,. Effects of high pressure on meat: A review, Meat Science 46 (3) (1997) 211-236.

[20] A. Sikes, A proposed mechanism of tenderizing post rigor beef using high pressure treatment, Meat Science 8 (2010) 390-399.

[21] N.R. Smit, J.W. Summerfield, J.E. Cannon, Use of high pressure processing to improve muscle quality by inhibiting post mortem glycolysis, Hormel Foods Corporation U.S. Patent, US20100048116A1, 2010. 